\title{
El medio-portal y los canales de actualidad
}

\author{
Dra. Elvira García de Torres \\ Universidad Cardenal Herrera-CEU Valencia
}

\begin{abstract}
RESUMEN
El presente artículo analiza el reto que Internet ha supuesto para los medios de comunicación tradicionales. La autora estudia cómo los medios informativos on line se han convertido en "un híbrido entre medios tradicionales con características propias de la digitalidad y servicios y contenidos propios de los portales". Así surge el medio-portal, mientras que los portales crean canales de actualidad para evitar la pérdida de usuario. El artículo recoge las principales diferencias en el tratamiento de la información por parte de ambos medios.
\end{abstract}

\section{ABSTRACT}

This article analyses the challenge that Internet has involved to traditional mass media. The author thinks about how on line media have evolved to a hybrid between traditional media with digital characteristics and contents of main doors. The "medio-portal" begins, whereas main doors create channels of news to prevent the loss of users. This article collects the main informative differences between both media.

Palabras claves: Internet/Medios de comunicación/Medios on line/Medio-portal/Canales de actualidad.

Key words: Internet/Media/On line Media/"Medio-portal"/Channels of news.

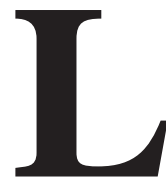

os conflictos mediáticos que salpican la historia de los medios de comunicación de masas, como el enfrentamiento entre los editores de la prensa escrita y la radio, en los años 30 del siglo XX, o la televisión y la radio en los cincuenta, tienen ahora nuevos protagonistas: medios digitales versus escritos, canales de actualidad y medios digitales, ¿medios digitales frente a medios audiovisuales?. Internet plantea un reto a todos los medios de comunicación de masas tradicionales.

La historia demuestra que la convivencia es posible, una convivencia basada en la reorientación, la adaptación y la complementariedad. Y la prensa escrita sigue presentando indudables ventajas: explica los hechos, crea opinión, es fácilmente accesible y legible y cómoda su lectura ${ }^{1}$.

1 Sobre competencia y complementariedad, V. MARTÍNEZ VEGA, J.A., El periódico: la producción periodística en el umbral del siglo XXI, Universidad Europea de Madrid CEES, Madrid, 2000, pp.75-82. 
Los esfuerzos en busca de vías de cooperación producen resultados a veces sorprendentes. En septiembre de 2000, la revista Forbes enviaba a sus suscriptores un pequeño escáner, bautizado como "Gato", que permite leer direcciones de páginas web en los medios de papel. Esta tecnología será adaptada por diarios como Dallas Morning News, Providence Journal o Milwaukee Journal en los EE.UU2. Juan Luis Cebrián, en La red, se muestra optimista: "siempre he defendido el carácter complementario de los medios de comunicación, su supervivencia en armonía si cada uno sabe adaptarse a los nuevos tiempos y operar desde el conocimiento de que ya no está solo"3.

El periódico en papel, un medio con una vida secular y avatares que le llevaron a una larga lucha que aún perdura por la libertad de expresión, a crisis de crecimiento por el incremento de las audiencias a finales del XIX y la disminución a lo largo del XX, y a una permanente adaptación a los avances tecnológicos, ha hecho las paces con prensa digital. La relación entre ambos se reinterpreta con fortuna: el periódico digital no es un nuevo medio, sino el resultado de la evolución natural de la hoja informativa del s. XVII.

El enfrentamiento no tiene sentido. Y es que sería poco honesto responsabilizar al nuevo medio del final de la prensa escrita, si tal llegara a producirse. No podemos ignorar la crisis que atraviesa desde hace unos años el periódico en papel y a la que ni el periodismo de servicio ni el cívico parecen poner fin.

En una interpretación a la inversa, el profesor Díaz Noci sugiere, como una de las causas que da lugar al nacimiento del periodismo electrónico interactivo multimedia, la "incapacidad de los periódicos de aumentar e incluso mantener sustancialmente el número de lectores, debido en gran parte al agotamiento de las fórmulas tradicionales"4. El periódico digital puede ser utilizado estratégicamente para llevar a los usuarios al periódico en soporte papel, creando una relación triangular que implica a los dos medios y al lector.

Javier Bardají, director de coordinación editorial del Grupo Correo de Comunicación, explicaba en mayo de 2000 cómo “... hace ahora tres años las inversiones que estábamos dedicando las empresas editoras a Internet eran mínimas, y que veíamos Internet como una amenaza, como algo agresivo que nos daba un cierto vértigo. Hoy empezamos a ver Internet como una oportunidad, como algo complementario, como una forma de obtener ingresos nuevos que no nos habíamos planteado y, como algo lo suficientemente relevante como para dedicar recursos independientes, nuevos y no recurrentes. Eso creo que está pasando en

2 “Forbes distribuye a sus lectores un escáner para que amplíen su información”, Diario del Navegante, 1/ 9/2000.

3 CEBRIÁN, J.L., La red, Suma de letras S.L, 2000, p. 99.

4 DÍAZ NOCI, J. y MESO AYERDI, K., Periodismo en internet. Modelos de la prensa digital, Servicio Editorial de la Universidad del País Vasco, Guipuzcoa, 1999, p. 21. 
todas las organizaciones, no sé si acertadamente o no, pero si repasamos algunos medios de comunicación, como El País y El Mundo, tienen ya redacciones dedicadas a Internet" .

En la actualidad, los diarios más destacados no sólo dedican esfuerzo e inversiones a sus ediciones digitales sino que promueven la difusión de contenidos digitales en nuevos soportes, como el teléfono móvil, los PDA o el correo electrónico, con consecuencias para la recepción. Para el usuario, surgen nuevas formas de acceso: un "acceso activo" a la información de portadas e índice, frente al "acceso pasivo" a titulares por e-mail o teléfono móvil, como señala Pou Amérigo 6 .

La difícil rentabilidad de la información digital es, sin embargo, un obstáculo para el desarrollo. A principios del año, 2000 The New York Times decide rescindir el contrato de 69 ciberperiodistas para tener un saldo positivo en los próximos dos años"7

Al enfrentamiento teórico, a la discusión sobre los retos que plantea la aparición de los medios digitales en el nivel técnico o tecnológico, sigue la batalla en el terreno del personal, con la aparición de las "redacciones digitales": la redacción tradicional se ve asaltada por unos extraños periodistas, que trasladan contenidos, producidos con gran esfuerzo por la redacción tradicional, al ciberespacio.

La profesora estadounidense Nora Paul advertía que la creación o transformación de las redacciones en redacciones "digitales" genera tensión en los medios tradicionales, por varias razones: ruidos logísticos (¿dónde situar la redacción digital?), técnicos (manejo de nuevos programas, lenguajes informáticos), culturales (¿qué significa exactamente "hora de cierre”?), así como perceptivos, actitudinales, históricos, éticos, de procedimiento, generacionales, motivacionales, esquizofrénicos, presupuestarios y organizacionales ${ }^{8}$.

Sin embargo, pasado el trauma inicial, caminamos a la convergencia de las redacciones; los "ciberperiodistas" han demostrado ser capaces de crear contenidos que enriquecen al medio tradicional, ayudados por el interés que despierta, en

5 Javier Bardají intervino en la mesa redonda "Los nuevos retos de la prensa digital", V Jornadas de Comunicación 2000 ¿Comunicación sin fronteras?, organizadas por Renfe y el CEU San Pablo de Valencia, Valencia, 4 y 5 de abril de 2000.

6 POU AMÉRIGO, María José, "El primer nivel informativo en la prensa electrónica: de las portadas a los servicios de titulares on-line", Actas del X Encuentro Latinoamericano de Facultades de Comunicación, celebrado en Sao Paulo, en octubre de 2000 (en prensa).

7 Clarin.com, martes 9 de enero de 2001. http://www.clarin.com/suplementos/informatica/noticias/nota_010109.htm

8 "Problemas de integración entre las redacciones tradicional y digital.", videoconferencia celebrada durante las Jornadas de Periodismo Digital, celebradas en Valencia, organizadas por la Asociación Valenciana de Investigadores en Comunicación y Periodismo Digital y Ciencias de la Información del CEU San Pablo de Valencia los días 12-13 de mayo de 1999 (www.avicpd.org) 
la actualidad, el mundo cibernético, y los veteranos encuentran nuevas vías para acceder a la información, navegando por el ciberespacio.

\section{El portal, nuevo medio informativo}

La estrategia comunicativo-empresarial del portal, desarrollada a finales de los años 90, es un nuevo caballo de batalla para la prensa tradicional. Víctor de la Serna, escribía en El Mundo un despiadado artículo en contra de las pretensiones informativas de los portales:

"Cuando leemos o escuchamos lo que El Mundo, la cadena Ser, Epoca o Tele 5 dicen, sabemos quienes son sus directores, sus redactores y sus comentaristas; conocemos su estilo informativo, su ideario editorial. Sus profesionales son periodistas, generalmente, de plantilla. Se debe suponer que (identro de la creciente indefensión de este oficio!) aún les quedan recursos individuales, colectivos y sindicales para defender su profesionalidad. (...)

Terra, Yahoo, Wanadoo... son otra cosa. No dicen ser medios de información. No establecen un contrato expreso o implícito con sus lectores. Mantienen en el limbo la situación de sus redacciones, que nos imaginamos redacciones virtuales, perdidas en el ciberespacio, sin cohesión ni responsabilidad ni más atributos que los de rellenar huecos con texto. Sin profesionalidad periodística.»"

Sin embargo, la incorporación de los canales de actualidad al sistema de medios es una realidad. Medios de comunicación son aquellas "empresas, públicas o privadas, cuyo cometido es emitir información de actualidad desde los soportes físicos y técnicos que la moderna tecnología ha hecho posible (...) todo ello sometido a la fragmentación del período, y que llamamos periodicidad"10. La información es uno de los servicios que ofrecen los grandes portales, a través -en muchas ocasiones- de los denominados canales de actualidad, que son, en realidad, páginas de noticias.

Manuel Gago y Xosé Pereira hacen referencia a las irrupción de empresas no periodísticas en los ámbitos de la información. Los portales o "centros de recursos" son caracterizados ya, en un texto sobre el nuevo periodismo electrónico, publicado en el año 2000, como un nuevo género de producto informativo: "Esta expansión de contidos centrouse, na información, a través da incorporación de información continuamente actualizada e pola creación de canles temáticas" ${ }^{11}$.

No se trata únicamente de una percepción academicista. En mayo de 2000, Julia Macuso Zabala, madre de la presunta miembro de ETA Julia Moreno

9 El Mundo, 8 de junio de 2000.

10 REY MORATÓ, J. del, "Medios", en BENITO, A., Diccionario de Ciencias y Técnicas de la Comunicación, Ediciones Paulinas, Madrid,1991, pp. 902-923.

11 LÓPEZ GARCÍA, X. y otros, O novo xornalismo electrónico, Edicións Lea, Santiago, 2000, p. 98. 
Macuso, ya presentaba una querella, en el Juzgado de Instrucción número 1 de Pamplona, contra Televisión Española, Canal 4, El Mundo, Diario de Noticias, Deia, El País, La Nueva España y el servidor de internet Terra. Estos medios, y la cursiva es mía, le habían imputado, por error, el delito de pertenencia a ETA.

Cuando Víctor de la Serna arremete contra los portales, más allá de la publicación del rumor sin contrastar -rémora de la información digital-, cuestiona la profesionalidad o el sentido de la profesionalidad en el portal. Medios en papel y medios on line constituyen ahora "medios tradicionales", guardianes del rigor, la exactitud y todos los prinicpios que rigen el buen quehacer periodístico, frente a los canales de actualidad de los portales. Quizá la dura competencia de los portales, multicanales multimedia, paradigma de la concentración de servicios y contenidos, hace temer, prematuramente, la decadencia de los medios informativos on line.

El rechazo a determinadas actitudes, pautas de comportamiento, estilos y organización mediática no es nuevo. Los principales modelos de diario representan principios incompatibles ${ }^{12}$. Ahora bien, no se cuestiona aquí un modelo de portal, sino el papel o la validez del portal como soporte de información periodística.

\section{Hibridación mimética: el medio-portal y el canal de actualidad}

La voz acusadora sorprende más todavía, cuando las diferencias entre portales y medios se diluyen. Tradicionalmente, se dibujan como rasgos característicos de los medios digitales on line la interactividad, la inmediatez y su carácter de soporte multimedia ${ }^{13}$.

El portal es la alternativa, nacida del medio digital, a los medios de comunicación de masas tradicionales, que también buscan expansión en la red. En Estados Unidos, se habla de la "guerra de los portales" desde principios del año 98. La palabra "portal", en el sentido cibernético, llega a nosotros importada del ámbito anglosajón. Es, en castellano, "zaguán o primera pieza de la casa, por donde se entra a las demás y en la cual está la puerta principal". Es un punto de partida, el distribuidor de recorridos para moverse por la red. Sólo que, en este caso, es una puerta que no conduce a ninguna parte, porque el negocio consiste en conseguir que el usuario viaje siempre por las tierras del portal, consumiendo sus productos, un número más que engrose la audiencia que se vende a los anunciantes.

En la actualidad, buscadores, juegos, conexión gratuita, tarifa plana y envío de mensajes a móviles parecen ser los grandes pilares de los portales.

12 V. CASASUS, J.M. y ROIG, X. La premsa actual. Introducció als models de diari, Edicions 62, Barcelona, 1981.

13 V. ARMAÑANZAS, E., DÍAZ NOCI, J. y MESO AYERDI, El periodismo electrónico, Ariel Comunicación, Barcelona, 1996. 
La información de actualidad es uno de los recursos tradicionales de este nuevo medio. Inicialmente, se trataba de noticias de última hora con origen en agencias de prensa. Sin embargo, algunos portales, en esa frenética carrera por ofrecer calidad y diferenciación, han iniciado la creación y desarrollo de sus propias redacciones digitales. Los recelos que despiertan estos equipos para la producción de noticias resultan inexplicables, comparando su acogida con la de diarios que nacieron para la red, como La Estrella Digital, Panorama Actual o Diari de Barcelona.

La denominación «canales de actualidad» que surge de los propios portales, frente al tradicional «medio informativo» y resulta poco familiar. «La mayoría de los periodistas que operamos en este sector - explica José Cervera, de Baquia.comodiamos (cordialmente) el término 'Portal' (vertical u horizontal) y asociados, como canal. Ambos están muy gastados y su significado se ha diluido mucho. Preferimos denominarnos 'medio de comunicación especializado'» ${ }^{14}$.

El canal de actualidad del portal guarda parelelismo con los noticiarios de las cadenas de televisión. Es un espacio para la información, en el marco general de una programación más o menos estructurada. No por ello es menos profesional.

Es cierto que la interrelación creciente entre información y espectáculo, que denuncia Furio Colombo, una de sus «últimas noticias sobre el periodismo», encuentra un microclima favorable en el portal, por la concentración de contenidos e intereses empresariales. Pero también en los medios digitales se impone el «juego» con la información, la noticia enmascarada, el «quiz» rápido o la votación sin reflexión, sin dejar de ser una actividad enmarcada en un entramado empresarial-comercial cada vez más complejo ${ }^{15}$. Todavía hoy, los medios digitales tienen que hacer frente a ya no tan nuevos problemas: “Cómo mantiene la credibilidad y la precisión enfrentándose a horas de cierre cada minuto?¿Son los sitios on-line responsables de lo que sucede en sus canales de charla?¿Deben establecer enlaces a sitios cuestionables que aparecen en las noticias?...."16

En uno y otro caso, la mirada crítica percibe idéntica desviación. Vicente Romano, prologando Atrapados a la red mediática de Pross, escribe que "Las actividades de los Disney, Bertelsmann, Kirch, Murdoch, Berlusconi, Polanco, etc., en todos los ámbitos de la comunicación: radiotelevisión, satélites, editoriales, prensa periódica, telefonía, Internet, música, cine, plataformas y vías digitales,

14 En julio de 2000, José Cervera es responsable de Baquia.com. Cursó el Master de Periodismo UAM/El País en la promoción de 1995 y trabajó en el diario Cinco Días de 1996 a 1999. Baquia cuenta con una redacción, organizada como tal y con periodistas experimentados; en ella, trabajan varios licenciados en Ciencias de la Información, Masters de Periodismo y algún economista. La mayoría tiene experiencia en medios tradicionales como La Vanguardia, Cinco Días, Expansión, Tiempo, Ideas y Negocios y en radio y televisión

15 V. REIG, R., Medios de comunicación y poder en España, Paidós, Barcelona, 1998.

16 The future of the printed press, European Journalism Centre, Maastricht, 1998, p. 47. 
etc., ponen de manifiesto hasta qué punto consideran la comunicación un sector estratégico para la cultura, la conciencia y la política"17.

En realidad, medios informativos y portales son las dos caras de la misma moneda y esto tiene su traducción en contenidos concretos, en la información: los portales incorporan los denominados canales de actualidad (equiparables al medio informativo tradicional) y los medios tradicionales aumentan su valor de portal para atraer a las audiencias.

El medio informativo digital on line de los primeros tiempos es ya historia del pasado. El medio on line ha evolucionado en una mutación natural, convirtiéndose en un híbrido entre medios tradicionales con características propias de la digitalidad y servicios y contenidos propios de los portales ${ }^{18}$. Así, frente al medio on line convencional, surge el medio-portal, con más capacidad de atracción para la audiencia y, por tanto, mayor potencial publicitario.

El Mundo es pionero en España en la renuncia a la metáfora visual del diario tradicional en la red, así como en la introducción de valor de portal: la charla digital, los juegos, la hemeroteca de libre acceso, cibertienda más tarde y diversificación temática con cinco portales propios (dinero, vinos, libros, salud y viajes). La estrategia, iniciada tempranamente, de la mano de Mario Tascón, ha dado sus frutos. El diario logra recuperar, en su versión digital, el espacio que marca el liderazgo de El País entre los medios tradicionales.

Poco a poco, los diarios comienzan a valorar el potencial de Internet, más allá de la interactividad; el gran agujero sin fondo admite múltiples contenidos, el usuario escoge, sin renunciar al formato clásico. En el medio digital, las noticias se distribuyen en secciones fácilmente reconocibles: Nacional, Internacional, Deportes... Titulares, entradillas, cuerpo de la noticia, viñetas; entrevistas, artículos, noticias... Todos esos elementos que forman parte de ese acervo común, constituyen un punto de encuentro entre el lector tradicional y el periódico on-line.

El pacto implícito que se establece entre un medio en su audiencia (lúdico, persuasivo o informativo) se apoya en esa información visual, formal, que cabe interpretar como información relacional, habla de la relación emisor-audiencia ${ }^{19}$. De hecho, el aspecto visual de los canales de actualidad de los portales remite a

17 PROSS, H., Atrapados en la red mediática. Orientación en la diversidad, Hiru, Guipúzcoa, 1999, p. 19.

18 En los trabajos «Las televisiones locales valencianas en la red: un estudio exploratorio» (comunicación presentada en el congreso Comunicar en la Era Digital, organizado por la UAB y celebrado en Barcelona los días 24 y 25 de febrero de 1999) e «Interactividad, información, promoción y valor de portal de las televisiones locales en la Red» (Revista Latina de Comunicación Social, La Laguna (Tenerife) - marzo de 2000 - número 27, www. http://www.ull.es/publicaciones/latina/aa2000tma/132/elvira.html) las profesoras María José Pou Amérigo y Elvira García de Torres han examinado, entre otros aspectos, el valor de portal de un conjunto de medios locales. Otros servicios con valor de portal, de origen reciente, son el envío de mensajes a móviles, la traducción y los diccionarios y la conexión gratuita.

19 V. RODRIGO ALSINA, M., Los modelos de la comunicación, Tecnos, Madrid, 1989 y WATZLAWICK, P., BEAVIN, J. y JACKSON, D., Teoría de la comunicación humana, Herder, Barcelona, 1997. 
esa configuración, recuerdan al usuario que se encuentran ante un medio informativo, no muy distinto de los que conoce; así pretende "vampirizar", recibir por mimetismo, la confianza que el lector deposita en su diario, una confianza ganada en esfuerzo secular.

Por su parte, el medio informativo se viste de portal para adentrarse y ganar la atención de la audiencia en la red. No parece que este movimiento haya generado una respuesta negativa, siquiera inquietud, entre los grandes portales. En España, el liderazgo de esta nueva forma de comunicarse es indiscutible: Terra, Eresmas, Ya, Yahoo... etc. dominan la comunicación digital. El grupo Correo anuncia, en febrero de 2001 la conversión a portales locales de las ediciones electrónicas de sus dos diarios ${ }^{20}$.

El éxito del portal se basa en la innovación, la calidad y multiplicidad de servicios, también en la publicidad. Actualmente, hay unos veinte portales en España, compitiendo por los casi cuatro millones de usuarios de Internet. Hace unos meses, apenas eran seis los portales. Se considera que la oferta de portales generalistas es excesiva para la demanda, por lo que cabe esperar estrategias de competencia más agresivas, en una guerra que se desata, en España, a finales de 1999.

En una relación emisor-audiencia mayoritariamente de servicio ${ }^{21}$, en la que atraer la atención de los usuarios garantiza la supervivencia, la multiplicación de la competencia para una audiencia finita implica una situación de suma-cero, de difícil resolución: negociar (integración) o luchar.

Para evitar la pérdida de usuarios, los portales crean canales de actualidad, es decir, sus propios medios de comunicación. Los medios aumentan su valor de portal, sin perder peso la información ni en cuanto a aspectos formales ni de contenido pero, además, los grupos multimedia crean portales, que dan acceso a sus medios de comunicación pero en los que el contenido básico no lo constituye la información: es el origen de Inicia (Grupo Prisa) y Jumpy (Grupo Correo).

\section{Portales y grupos multimedia}

-Un portal es el origen/núcleo de un grupo multimedia (Eresmas) •El grupo multimedia crea su portal (Telefónica/Terra 11-1999 y Prisa/Inicia 22000) -El portal y un grupo multimedia se asocian ( AOL y Time Warner; Correo y Jumpy de Finninvest/ 6-2000) •El grupo multimedia adquiere un portal (Correo/Ozú 21-2-2001) •El portal y el grupo multimedia colaboran (EITB+Yahoo) •Los portales no operan en el sector tradicional (Lycos, Msn, Yahoo, Navegalia, World on Line, Yupi.com, guay.com, Arrakis, Canal21, Excite.es, Wanadoo, Telepolis Ya.com) 
De los principales portales con grandes audiencia en España (Lycos, Msn, Yahoo, Eresmas, Navegalia, World on Line, Yupi.com, guay.com, Arrakis, Canal21, Excite.es, Wanadoo, Telepolis Terra.es/ Ya.com) sólo Terra tenía un referente en el sector tradicional de medios de comunicación. El resto opera en la red y en el segmento de telefonía móvil, con la excepción de Eresmas: «La evolución de Telefónica «difiere de las operadoras tradicionales, que en general no han tomado posiciones en estos campos, y sí se han posicionado todas en Internet» ${ }^{22}$.

El grupo Telefónica, sin referente en el sector de la prensa escrita, se ha convertido en cabeza de grupo, actor pionero en la escena digital. Inicia y Jumpy -pese a sus dificultades- son ejemplo de convergencia entre viejos y nuevos medios. Los portales forman parte de la estructura mediática tradicional lo que conduce a relaciones más de cooperación que de competencia.

Desde Inicia, el navegante puede dirigirse a cualquiera de los medios del grupo Prisa. Y Jumpy, con participación del grupo Correo, se benefició en su momento del éxito de «Gran Hermano», un programa del canal Tele 5 en el que el grupo forma parte del accionariado. Portales y medios digitales tienen que reconsiderar su relación.

Medios y canales frente a frente: «Cuatro presuntos terroristas detenidos...»

Del papel de los portales en el nuevo sistema digital informativo dice mucho la presencia de Noelia Fernández, responsable de Yahoo España, en el curso "Los desafíos del periodismo en la era electrónica", celebrado San Lorenzo del Escorial en septiembre de 2000. En el marco de los cursos de verano de la Universidad Complutense de Madrid, la responsable de Yahoo manifestó que los trabajadores de la prensa electrónica deben: "combinar la profesionalidad y la verificación de las fuentes, características del periodismo tradicional, con el uso de nuevos intrumentos y la capacidad de intermediación con otros profesionales, que requiere la prensa de Internet".

En el mismo curso, Mario Tascón, director de contenidos de Prisa.com, reconocía que muchos internautas prefieren informarse acudiendo a un portal de consultas rápidas antes que leyendo un periódico electrónico, asociando el éxito de un medio de comunicación en la red con el tiempo ${ }^{23}$. Pero un lector que valore la rapidez de acceso a la información en el portal, puede estar peor informado. Un usuario crítico y habituado a relacionarse con los medios puede notar la diferencia.

El estudio de un caso particular, la respuesta de los medios a las detenciones de cuatro presuntos terroristas llevadas a cabo por la policía francesa y española

22 PLAZA BAYÓN, C. (Director), Telecomunicaciones y tecnologías de la información, Ediciones Tiempo, 1999, p. 101.

23 "El periodismo electronico utilizará un nuevo lenguaje”, según los expertos", El País, 7/09/2000. 
la noche del sábado, 16 de septiembre de 2000, nos lleva a plantear como hipótesis que los "medios tradicionales" on line (rapidez en la respuesta, edición, jerarquización...) ofrecen información de mayor calidad que los canales de actualidad de los portales ${ }^{24}$.

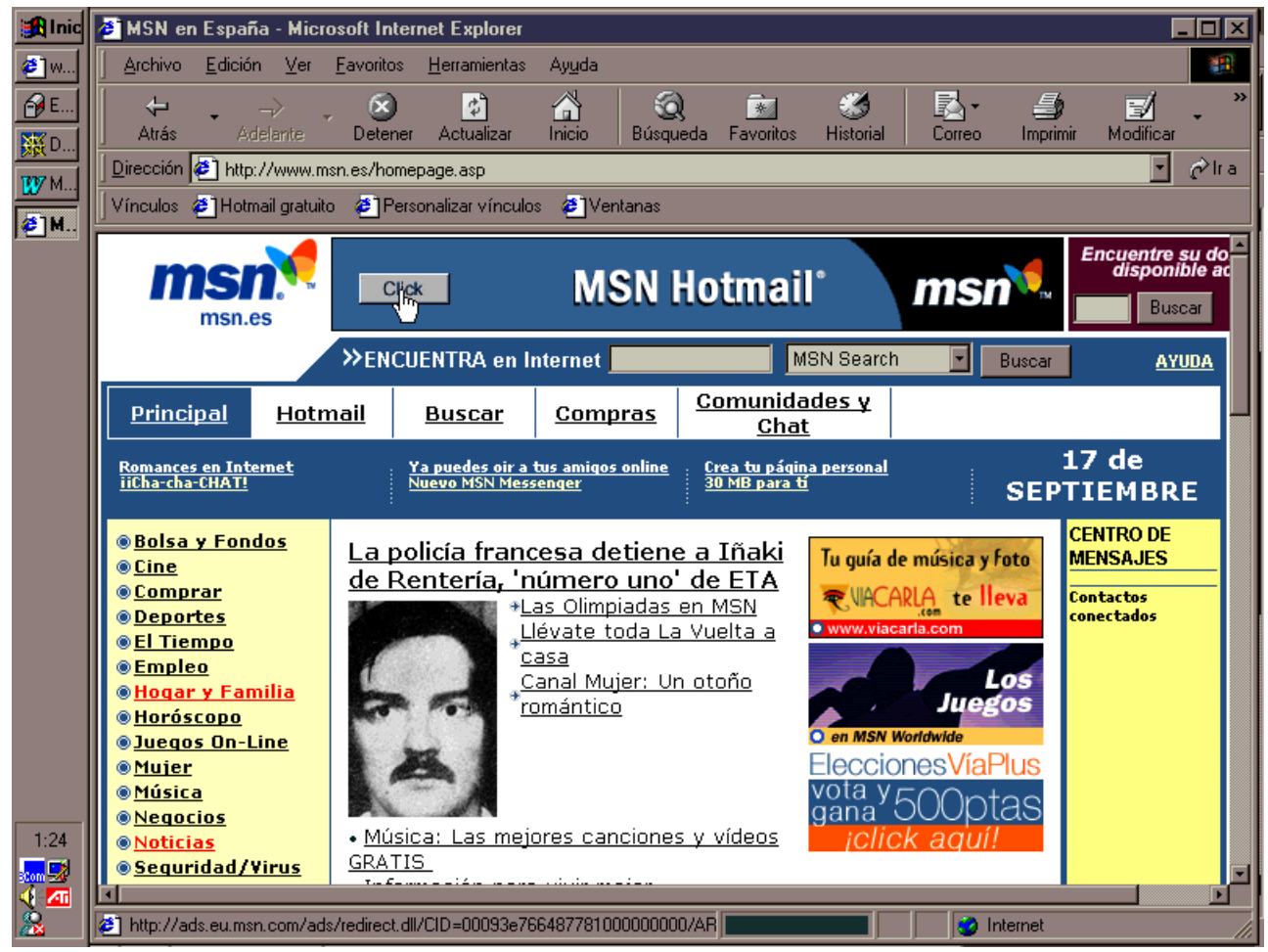

Cuatro de los periódicos on-line examinados a partir de la una de la madrugada del día 17 de septiembre de 2000 (El País, El Mundo, ABC, La Razón) sitúan la información en portada, con tratamiento tipográfico que subraya la importancia que el medio concede a la noticia e incorporando información exhaustiva sobre la identidad y la posibilidad de consultar el historial de los cuatro detenidos.

24 El periodista Florencio Domínguez, redactor-jefe de la agencia de noticias Vasco Press, ha colaborado revisando y aportando información relativa al caso. 


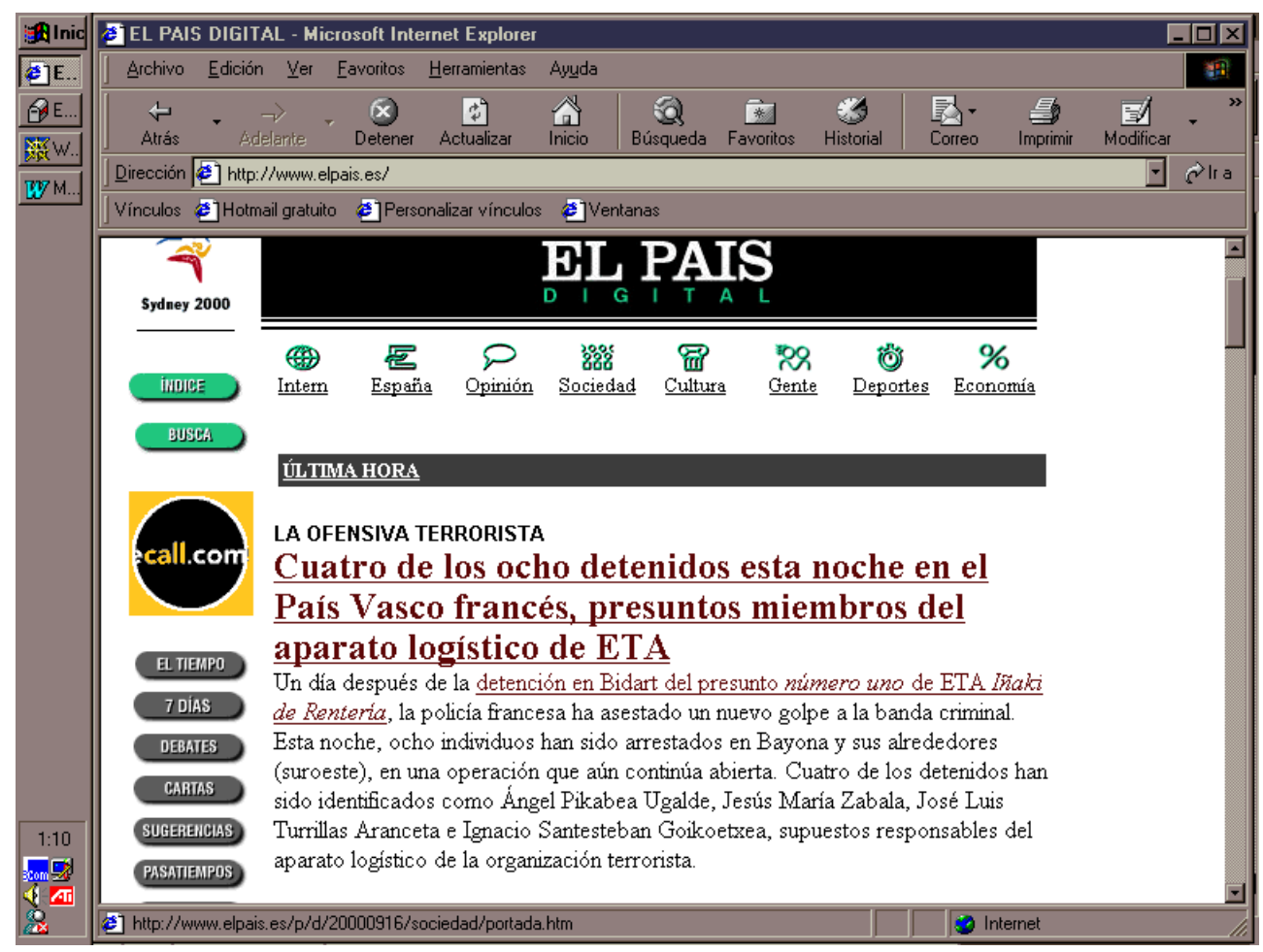

La comparación entre página principal del portal MSN y la portada El País Digital ilustra la diferencia encontrada entre algunos portales y los medios de información. La información que ofrece MSN no recoge los acontecimientos más recientes. Es equiparable a la edición de la prensa escrita, como sucede con $L a$ Vanguardia; transcurridas varias horas de las detenciones, mantenía como noticia principal de portada la detención de Iñaki de Rentería, una información del día anterior, algo que también sucede en los medios locales de Valencia Las Provincias y Levante-EMV. Por el contrario, El País, ABC, La Razón y El Mundo actualizaban sus páginas de madrugada.

\section{La respuesta on-line a la detención de cuatro terroristas*}

El País Información en portada: « Cuatro de los ocho detenidos esta noche en el País Vasco francés, presuntos miembros del aparato logístico de ETA», con entradilla y enlace a los historiales.

$A B C \quad$ En portada: «Golpe policial al entramado de ETA en Francia tras la detención de Iñaki Rentería». Es también noticia de última hora, desarrollada ampliamente y con enlaces al historial de los detenidos. 
La Razón Noticia de última hora en portada: «La guardia civil asesta en Francia un duro golpe a los «aparatos de logística» y de mugas de eta» (actualizada a las 00:40). La noticia se desarrolla ampliamente, con información procedente de la agencia Vasco Press. La información principal en portada es «Cae el número uno de eta».

El Mundo «Cuatro miembros del aparato logístico de ETA, entre los ocho detenidos en Francia», con antetítulo (Tras el arresto de Iñaki de Rentería»), entradilla y enlaces. Actualizado a las 01.02.

La Vanguardia Titular: «El número uno de ETA, detenido en el sur de Francia», con entradilla ( «La policía francesa detuvo ayer al presunto número uno de ETA») y enlaces.

Navegalia En el canal de noticias, Última hora de España «Desmantelado aparato logístico ETA con detención de 4 dirigentes», titular de agencias sin editar.

Terra En página principal: «Lucha antiterrorista: nuevas detenciones en Francia». En el canal de actualidad: «Por el momento, no se ha facilitado ni la identidad ni las nacionalidades de las personas arrestadas». La información se desarrolla, sin embargo, en Última Hora.

$\mathrm{Ya}$ Noticia de portada: «Más detenidos en Francia», con entradilla. Con la firma de agencias y entradilla, se citan los nombres de los detenidos.

Yahoo Titular en recuadro de última hora en página principal: «Detenido en Francia el número uno de ETA». En el canal de actualidad se transcribe un teletipo de Europa Press «Detenidas en Francia ocho personas, entre ellas cuatro dirigentes etarras del aparato logístico».

Eresmas En portada la información más actualizada sobre el tema es el traslado de Iñaki de Rentería a París. En el canal de actualidad de España: «Nuevas detenciones en Francia tras el arresto de Iñaki de Rentería», especificándose que las fuentes no revelaron las nacionalidades ni las identidades de los detenidos. Fechada a las $21.58 \mathrm{~h}$.

MSN Información de última hora en página principal: «La policía francesa detiene a Iñaki de rentería, «número uno de ETA». En noticias de última hora puede leerse «Detenidas en Francia ocho personas, entre ellas cuatro dirigentes», una información de Europa Press.

Lycos En el canal de noticias, es la noticia destacada en Nacional. Entradilla sin titular.

Guay Noticia de portada: «Rekalde tiene heridas de gravedad y será operado mañana a las nueve de la mañana», con entradilla.

World on line Canal de noticias: «Cuatro presuntos etarras más, detenidos en Bidart». Recoge los nombres de cuatro de los etarras detenidos, en una noticia breve, procedente de EFE. 
Wanadoo En portada no incluye información. En el canal de noticias de «Detenidos en Francia cuatro dirigentes del aparato logístico de ETA». En la información no se indican los nombres de los detenidos.

Yupi Noticias de España: «Encontradas 8 granadas cerca del museo Chillida».

* Consultas efectuadas a partir de la 1.00 del 17 de septiembre de 2000. Las detenciones se efectúan a partir de las $19.40 \mathrm{~h}$. y las informaciones de agencias comienzan a circular cerca de las 22.00 horas.

Ya.com destaca entre los portales. Su página principal invitaba a leer como titular, en portada, «Más detenidos en Francia». En Navegalia fue noticia de última hora, no de portada, así como en Terra y en MSN, Eresmas, Wanadoo y Lycos. En Terra podía leerse, sin embargo, a la una de la madrugada, que la identidad de los detenidos no había sido facilitada, cuando una buena parte de los medios ofrecía el historial de los cuatro presuntos terroristas.

Ahora bien, las páginas de Yupi y Guay.com son un ejemplo de hieratismo ante la evolución de los acontecimientos. Yupi informa en la madrugada del día 17 del hallazgo de 8 granadas cerca del museo Chillida. Esta información aparecía en ABC, procedente de Vasco Press, fechada a las 14.41. Por su parte, Guay.com tiene como noticia principal la operación del político vasco Recalde, herido en atentado el día 14 de septiembre al anochecer, que ya había sido operado el día 15 por la tarde.

\section{La información en los canales de actualidad}

Como medios informativos, los portales están sujetos a las mismas presiones y tensiones que los medios de comunicación tradicionales. En primer lugar, la necesidad de materia prima. En segundo lugar, lograr la rentabilidad. El coste de la recogida y el tratamiento de la información no puede ser superior a los ingresos que genera la venta de las noticias a los usuarios. En ese difícil equilibrio, los portales se juegan la calidad de la información.

\section{Calidad informativa de los portales en España*}

\section{Calificación}

Sobresaliente

Notable

Bien

Aprobado

\section{Portal}

Terra y Ya.com

Lycos, Msn, Yahoo, Eresmas, Navegalia, World on Line, Yupi.com, guay.com

Arrakis, Canal21, Excite.es, Wanadoo

Telepolis

*Fuente: José Valladares, «Objetivo: Desbancar a Terra», Actualidad Económica, julio de 2000 
Distinguimos entre portales proveedores/transmisores y portales productores de contenidos informativos ${ }^{25}$. Los segundos son los que alcanzan la calificación más alta en la evaluación que realiza el periodista de Actualidad Económica.

Una gran parte de los portales españoles carece de redacción propia y depende exclusivamente de la información que reciben de una o varias agencias de prensa. Entre los portales proveedores se pueden diferenciar aquellos que dan un tratamiento mecánico, tecnológico a la información que reciben de agencias y los que editan, en mayor o menor medida, las noticias. En el primer caso, sí ocurre que «o portal convértese practicamente nun terminal duhha axencia» ${ }^{26}$.

Los portales proveedores son canales para información de agencia, que recibe menor o mayor tratamiento en la fase de edición (Yahoo, Eresmas...). Los portales productores cuentan con equipos de trabajo, auténticas redacciones periodísticas, un equipo de personas que produce, selecciona, valora y edita información (Terra, Ya.com).

Unos y otros publican fundamentalmente información, con ausencia de contenidos editorializantes. Ésta es una función característica de los medios tradicionales, especialmente en la prensa escrita. Pero pocos portales incluyen textos de columnistas y, en ningún caso, editoriales. El portal no se sitúa ante los acontecimientos. Permanece ajeno al tercer nivel de interpretación del periódico que, «además de comunicar las informaciones así elaboradas, trata también de situarlas y ambientarlas para que se comprendan (reportajes, crónicas) y de explicarlas y juzgarlas (editorial y, en general, comentarios) ${ }^{27}$.

En términos funcionalistas, la lectura de la información de los canales de actualidad requiere más tiempo y esfuerzo al reducirse la actividad editorial (evaluación e interpretación de las noticias) ${ }^{28}$.

\section{Problemas de los contenidos informativos de los portales}

Falta de jerarquización de la información. Ausencia de opinión. Titulares y redacción de los textos poco cuidados. Preeminencia del titular. Limitados recursos humanos. Escasa preocupación por la «calidad» (cita de fuentes...). Corresponsales autónomos en la selección de las noticias. Gran dependencia de la información de agencia. Dificultad de acceso a los acontecimientos (competencia directa con promotores). Desaparición de la mancheta. Falta de reacción ante información imprevista.

25 Denominamos portales proveedores a los que no producen contenidos informativos. Su fuente principal son las agencias de prensa, sobre cuyo material se realiza una tarea de edición mayor o menor.

26 LOPEZ GARCÍA, X. y otros, op. cit., p. 94.

27 GOMIS, L., Teoría del periodismo. Cómo se forma el presente, Paidós Comunicación, Barcelona, 1991, p. 38 .

28 V. WRIGHT, Ch. R., Comunicación de masas, Paidós Studio, México, 1990, pp. 19-24. 
La presentación de la información no es homogénea. Algunos portales -es el caso de Yupi- optan por la exposición indiscriminada de titulares de mayor o menor actualidad, sin jerarquizar ni ordenar temáticamente o geográficamente. El navegante se encuentra con un listado de noticias, sin una sección de opinión que le ayude a situar cada acontecimiento en un contexto o marco de interpretación que favorezca su asimilación. En cambio otros, como Terra, destacan la noticia del día, las noticias más importantes y se ajustan al formato de presentación de los medios tradicionales. El género predominante es la noticia, también con diferencias formales en la titulación; en muchas ocasiones llega el titular de agencia, en otras la noticia se edita cuidadosamente.

En la información digital, un elemento jerarquizador importante es la portada de las secciones. Es necesario «proceder a jerarquizar las noticias para que el público diferencie con rapidez y precisión los temas que el medio de comunicación ha seleccionado como los más importantes de la jornada» ${ }^{29}$. En la información de algunos los canales de actualidad se nota la ausencia de criterios de jerarquización: orden de presentación de las noticias y tamaño de las noticias. En este sentido, el formato elegido por la versión digital del diario $\mathrm{ABC}$ (www.abc.es) en enero de 2001 se aproxima a las fórmulas de los canales de actualidad antes que a las propias del periodismo tradicional.

La información recogida al examinar el comportamiento de los medios ante una noticia «relativamente» imprevista, la detención de cuatro presuntos terroristas en Francia, indica que existen notables diferencias en el tratamiento de la información por parte de medios on line y canales de actualidad de los portales. En estos casos, la capacidad de reacción no depende únicamente del número de prensa implicadas en la elaboración de las noticias, sino de su especialización, conocimiento de fuentes, contactos en el medio ${ }^{30}$.

El diario ABC publica la noticia procedente de Vasco Press en última hora, pero poco después reorganiza la portada para situar, en lugar preferencial, el titular «Golpe policial al entramado de ETA en Francia tras las detención de Iñaki de Rentería». La noticia era conocida por los periodistas horas antes de ser publicada. Los periodistas de la sección Nacional estaban preparados para ofrecer la información cuando ésta no pusiera en peligro la acción policial.

La redacción de la versión digital de $A B C$ se compone de 16 personas, pero los contenidos de la versión digital del medio son elaborados conjuntamente por el total de la redacción, que suma 361 periodistas. La noche del 16 de septiembre de 2000, la redacción digital actualiza la información de última hora, pero después, en cuanto las autoridades oficiales autorizan la difusión de la información, los

29 ARMENTIA VIZUETA, J.I. y otros, El diario digital, Bosch, Barcelona, 2000, p. 188.

30 V. QUESADA, M., Periodismo Especializado, Ediciones Internacionales Universitarias, Madrid, 1998. 
periodistas de Nacional aportan el grueso de los datos. Habitualmente, la redacción digital recibe información de los periodistas que trabajan en las distintas secciones y en el extranjero, con la conciencia de que todos trabajan para las dos ediciones del medio, papel y on line. La redacción digital, por su parte, aporta la información sobre Internet y nuevas tecnologías tanto para el soporte papel como digital.

En El País Digital siete periodistas trabajan en turnos, desde las ocho de la mañana a la una de la madrugada. A partir de esa hora, la redacción de noche, diez periodistas y tres técnicos asumen el volcado, fundamentalmente, pero también la actualización de la información, hasta las cuatro. El grueso de la información lo constituye el contenido del diario en papel, algo de lo que carecen, como punto de partida, los portales españoles.

Los medios de comunicación tradicionales establecen una serie de rutinas de producción para garantizarse un flujo constante y regular de noticias. Los portales, como cualquier otro medio, necesitan esos retazos de actualidad, trozos de realidad, para ofrecer noticias a sus usuarios. Dos piezas clave en las rutinas productivas de los medios son las agencias de información y los gabinetes de prensa.

En los portales, las agencias constituyen uno de los grandes pilares de la captacion de noticias. Éstas, conscientes de las necesidades informativas que despierta Internet en los «nuevos medios», han desarrollado estrategias dirigidas especialmente a los portales y a los usuarios de Internet. Destacan dos: el ticker y la información para medios digitales. En España, EFE y Europa Press se reparten el mercado de los portales.

La agencia Europa Press, a distancia de EFE en el sector tradicional, ha conseguido superar esa diferencia en la red. Europa Press tiene actualmente algo más de cuarenta clientes en Internet, entre los que se encuentran medios digitales, medios tradicionales y, por supuesto, portales, generalistas y especializados. Esta agencia ofrece un servicio de noticias y opinión para medios digitales y se presenta como el principal proveedor de contenidos para Internet del ámbito hispano. Ofrece información especializada de ocio y finanzas, además de los contenidos generalistas para páginas web, correo electrónico y teléfono móvil. Varios portales utilizan los servicios de Europa Press ${ }^{31}$. Es el caso de Arrakis, Jumpy, Canal 21, MSN, Ya, Yahoo, UOL, Eres Mas, Lycos, Wanadoo, Wol, Excite y Guay. Europa Press también sirve información a portales especializados como Nosotras.com y Secretariaplus.com, además de medios tradicionales (La Razón) y empresas como Sanitas o Esic.

31 Las agencias EFE y Europa Press, los portales Yahoo, Ya, Eresmas, Baquia, Servifútbol, Msn y Guay (datos de julio de 2000) y los diarios ABC y El País (consultas efectuadas en septiembre de 2000) son la fuente de la información que se cita en estas páginas. 
La agencia EFE, por su parte, tiene como clientes de Internet, entre otros, a Terra, Navegalia, Invertia, Ya.com, Recol, Libre Directo, Sports, Net Click, Parque Empresarial, Eres Mas, Uni 2, Infobolsa, Atibex, Deporweb y Navaltur.

\section{A modo de conclusión}

Los denominados canales de actualidad de los portales constituyen un medio informativo, un medio periodístico equiparable a cualquiera de los conocidos (radio, prensa escrita en papel y on-line, televisión). Negar el status de medio informativo a los canales de actualidad supone, por ende, negarla a los medios nacidos para la red, como La Estrella Digital o Panorama Actual.

Tampoco parece oportuno hablar de la «calidad» o «profesionalidad» de los medios tradicionales como contraposición a los portales. Los medios tradicionales no escapan a la mirada crítica, desde las consecuencias del establecimiento de rutinas productivas a casos concretos de tergiversación, mentira o exageración ${ }^{32}$. En función de los modelos informativos que se tomen como referencia, la audiencia interpreta, admite y aplaude distintos grados de alejamiento de la realidad.

La capacidad productiva de los portales en el año 2000, en cuanto a contenidos informativos, es mínima, y no se corresponde con el volumen de audiencia que generan, pero las expectativas de futuro son distintas. De la Serna, adjunto para Relaciones Internacionales de El Mundo, aseguraba en julio de 2000 que «las empresas de telecomunicaciones consideran que el periodismo es sólo contenido y eso es sinónimo de «relleno»». Le respondía el director de servicios de acceso de Terra Networks: «Yo no puedo dar el mismo peso a la información porque no soy un periódico ni una empresa de radio» ${ }^{33}$. Y sin embargo, unos meses después, en enero de 2001, Miguel Ángel Aguilar, comienza su artículo sobre la condecoración a Melitón Manzanas "En unas declaraciones del pasado día 24 al canal de actualidad del portal Terra el ministro del Interior..." 34 .

Los criterios de calidad mínimos están garantizados cuando se recurre a información de agencias solventes. Europa Press y EFE son las principales referencias en la red, en el ámbito de los portales; estas agencias han realizado en los últimos tiempos un esfuerzo de adaptación a esta nueva forma de transmitir información. Los canales de actualidad no están a la altura de los medios escritos

32 Recordamos, por ejemplo, la difusión, por parte de las televisiones españolas de alcance nacional, de un video grabado por la policía, que se emitió sin saber y, por tanto, advertir a la audiencia de que se trataba de una recreación ((Levante-EMV, 17-11-1999). O la publicación de una falsa agresión de skins, que tuvo su origen en una información del Gabinete de prensa de la Polícía de Barcelona (El País, 21-3-2000).

33 El Diario del Navegante de El Mundo Digital (27 de julio de 2000) publicaba la noticia «De la Serna asegura que hay poco periodismo en internet», donde se recogen declaraciones de los participantes en el seminario Gutenberg.com, celebrado en la UIMP de Santander, en julio de 2000.

34 Aguilar, M.A., «A quién condecoramos», El País, 30 de enero de 2001, p. 15. 
de referencia en la red, pero tampoco puede decirse que la información que proporcionan carezca, generalizando, de rigor o actualidad.

La escasez de recursos humanos repercute no sólo en la selección de la información, sino también en la fase de tratamiento y edición, el segundo paso de la selección, la jerarquización. La mayor parte de los portales son proveedores de información, cuentan con una red profesional de captación de información (agencias de prensa), ajena al medio. No es razonable esperar los mismos resultados del trabajo de una persona, en la producción de noticias, frente a los más de trescientos periodistas con los que cuenta un medio tradicional. Incluso los canales que cuentan con equipos más amplios, quedan muy lejos de las cifras de los medios escritos/on line.

Obviamente, asumiendo estas diferencias de recursos, cabe exigir a los portales idéntica responsabilidad, rigor, precisión y actualidad que a los medios tradicionales. Sin poner en duda que la información es en todos los casos rigurosa y precisa, quizá habría que recomendar un esfuerzo en la edición y en la actualización a los canales de actualidad de los principales portales que operan en España. Pero esta recomendación también es extensible a un amplio número de periódicos digitales, en el ámbito local, e incluso a las distintas cadenas de radio y televisión que, por el momento, no dan muestra de su potencial informativo en la red.

Un medio en el que la inmediatez permite ofrecer información de manera sincrónica en relación al acontecimiento necesita contar con periodistas especialistas, expertos que puedan adelantarse a la noticia y preparar material dispuesto para ser editado en el momento en que el acontecimiento internamente previsto tenga lugar. Las diferencias no están tanto en dar a conocer la noticia sino en la profundidad, la exhaustividad y el tratamiento editorial, la emisión de datos con certeza y en el menor tiempo posible. 